\title{
Productivity for Horizontal Wells in Low-Permeability Reservoir with Oil/Water Two-Phase Flow
}

\author{
Yu-Long Zhao, ${ }^{1}$ Lie-Hui Zhang, ${ }^{1}$ Zhi-Xiong He, ${ }^{2}$ and Bo-Ning Zhang ${ }^{1}$ \\ ${ }^{1}$ State Key Laboratory of Oil and Gas Reservoir Geology and Exploitation, Southwest Petroleum University, \\ Chengdu, Sichuan 610500, China \\ ${ }^{2}$ School of Sciences, Southwest Petroleum University, Chengdu, Sichuan 610500, China \\ Correspondence should be addressed to Yu-Long Zhao; 373104686@qq.com
}

Received 30 October 2013; Revised 1 February 2014; Accepted 30 April 2014; Published 22 May 2014

Academic Editor: Paulo Batista Gonçalves

Copyright (C) 2014 Yu-Long Zhao et al. This is an open access article distributed under the Creative Commons Attribution License, which permits unrestricted use, distribution, and reproduction in any medium, provided the original work is properly cited.

\begin{abstract}
This paper presents a semianalytical steady-state productivity of oil/water two-phase flow in low-permeability reservoirs with both top and bottom boundaries closed which takes the permeability stress-sensitive and threshold pressure gradient into account. Using the similar approach as Joshi's (1988), the three-dimensional (3D) horizontal well problem is divided into two two-dimensional problems (2D), and then the corresponding nonlinear steady seepage mathematical models in vertical and horizontal planes are established. Through the separation of variables method and equivalent flow resistance principle, the productivity equation of horizontal well is obtained. The liquid and oil productivity with different influential factors are plotted, and the related effects are also analyzed. This paper expanded the conventional productivity equations of single phase into multiphase flow which have both theoretical and practical significance in predicting production behaviors in such reservoirs.
\end{abstract}

\section{Introduction}

With the development of drilling technology and the reduction of its cost, more and more horizontal wells have been used in low-permeability reservoirs, fractured reservoirs, multilayered reservoirs, and bottom water drive reservoirs. And the steady-state productivity of horizontal well is always a hot topic for the petroleum engineers. After several decades of development and research, many methods, including analytical method, conformal transformation method, potential superposition method, equivalent flow resistance method, and the point source function method, were proposed to calculate it [1-9].

Merkulov [1] and Borisov [2] derived analytical productivity equation of the horizontal well with single oil phase flow. Giger et al. [3, 4] and Karcher and Giger [5] developed a concept of replacement ratio, $F R$, which indicates the required number of vertical wells to produce at the same rate as that of a single phase from formation well to horizontal well. Reiss [6] proposed an equation to calculate the productivity index for horizontal well. Thereafter, through subdividing the $3 \mathrm{D}$ flow of horizontal well into two 2D problems (flow on horizontal plane and vertical plane, resp.), Joshi [7] derived an equation to calculate the productivity of steady-state horizontal well, which is the most popular method nowadays.

Babu and Odeh [8] proposed an equation to calculate the productivity of horizontal well under the assumption that the shape of the drainage volume is box and all the boundaries are closed. Renard and Dupuy [9] derived the flow efficiency equation for horizontal well in anisotropic reservoir with the consideration of skin factor. Then, Helmy and Wattenbarger [10] and Billiter et al. [11] also proposed their corresponding equations to calculate the productivity. Anklam and Wiggins [12] obtained the steady-state productivity with the consideration of the mechanical properties of fluid flow into the wellbore. Using the steady-state point source function theory, $\mathrm{Lu}$ [13] achieved the productivity equations for horizontal wells under different boundary conditions.

Most of the productivity equations of horizontal well mentioned above are mainly concentrated on single oil phase flow, but the ones related to multiphase are rare. In this paper, we employ the same method described by Joshi [7] and derived a steady-state productivity formula for a horizontal well with oil/water two-phase flow problem 


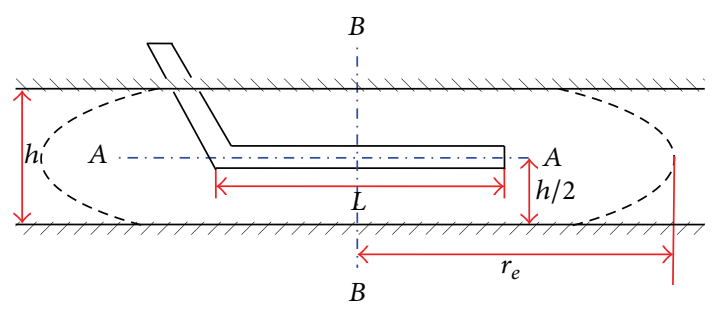

Figure 1: Schematic of a horizontal well in a top and bottom boundaries closed reservoir.

in low-permeability reservoir, which takes the permeability stress-sensitive and threshold pressure gradient into account.

\section{Theoretical Analysis}

2.1. Physical Model. Figure 1 is a schematic of a horizontal well drilled in low-permeability oil reservoirs. To make the problem more tractable, the following assumptions are made: (1) the reservoir is horizontal, homogeneous with uniform thickness of $h$, and both the top and the bottom boundaries are closed; (2) the well length and radius are $L$ and $r_{w}$, respectively, the well is located at the center of the formation, and the pressure at the drainage boundary is $p_{i}$ with the radius of $r_{e}$; (3) two-phase fluid flows from the reservoir to the well at a constant bottomhole pressure $p_{w f}$ and ignore the gravity and capillary pressure effects.

To simplify the mathematical solution, the $3 \mathrm{D}$ problem is subdivided into two $2 \mathrm{D}$ problems [7]. Figure 2 shows the following subdivision of the ellipsoidal drainage problem: (1) fluid flow into the horizontal well in the horizontal plane; (2) fluid flow into the horizontal well in the vertical plane.

2.2. Permeability Model in Low-Permeability Reservoir. In this paper, we use the exponential permeability model to describe the relationship between permeability and pore pressure [1420]. This model is based on a permeability modulus, $\alpha_{k}$, which is defined as the following:

$$
\alpha_{k}=\frac{1}{k} \frac{\partial k}{\partial p}
$$

Integrating of (1) with $p$ from $p_{i}$ to $p$ yields

$$
\frac{k}{k_{i}}=\exp \left[-\alpha_{k}\left(p_{i}-p\right)\right]
$$

where $\alpha_{k}$ is the permeability modulus, $\mathrm{MPa}^{-1} ; \mathrm{p}$ is the formation pressure, $\mathrm{MPa} ; p_{i}$ is the initial pressure, $\mathrm{MPa} ; k_{i}$ is the permeability at initial condition, $\mathrm{D} ; k$ is the permeability at current condition, D.

2.3. Threshold Pressure Gradient in Oil/Water Two-Phase Flow. According to the experimental investigations (the schematic of core sample experiments is shown in Figure 3), an appropriate form of Darcy's law with a threshold gradient should be used as [21-28]

$$
v= \begin{cases}-\frac{k}{\mu}\left(\frac{\partial p}{\partial r}-G\right), & \frac{\partial p}{\partial r}>G \\ 0, & \frac{\partial p}{\partial r} \leq G\end{cases}
$$

where $v$ is velocity of the fluid flow, $\mathrm{m} / \mathrm{s} ; \mu$ is the fluid viscosity, cp; $r$ is the radius, $\mathrm{m} ; G$ is the threshold pressure gradient, $\mathrm{MPa} / \mathrm{m}$.

2.4. Flow in a Horizontal Plane. Figure 2(a) shows a schematic of fluid flow to a horizontal well in a horizontal plane. The drainage area is an ellipse and introduces

$$
\frac{z}{L / 2}=\frac{1}{2}\left(\xi+\frac{1}{\xi}\right),
$$

by defining $z=x+i \cdot y$ and $\xi=u+i \cdot v=r_{e H} \cdot e^{i \theta}$. Substituting them into (4) and then equating the real and imaginary parts yield

$$
\begin{aligned}
& \frac{x}{L / 2}=\frac{1}{2}\left[r_{e H}+\frac{1}{r_{e H}}\right] \cos (\theta), \\
& \frac{y}{L / 2}=\frac{1}{2}\left[r_{e H}-\frac{1}{r_{e H}}\right] \sin (\theta) .
\end{aligned}
$$

The real equation of the elliptical drainage area can be described as

$$
\frac{x^{2}}{a^{2}}+\frac{y^{2}}{b^{2}}=1,
$$

where $a$ and $b$ are the major and minor axes of the ellipse, $m$.

Combing (5) with (6), we have

$$
r_{e H}=\frac{a+b}{0.5 L}
$$

Moreover, $+L / 2$ and $-L / 2$ represent foci of the ellipse, which have the following relationship with $a$ and $b$ :

$$
a^{2}-b^{2}=\left(\frac{L}{2}\right)^{2}
$$

The drainage radius of horizontal well, $r_{e}$, can be obtained by equaling the areas of a circle and ellipse, which is

$$
r_{e}=\sqrt{a b}
$$

Combing (9) with (8), we have

$$
\begin{gathered}
a=0.5 L\left[0.5+\sqrt{0.25+\left(\frac{2 r_{e}}{L}\right)^{4}}\right]^{0.5}, \\
b=\sqrt{a^{2}-\left(\frac{L}{2}\right)^{2}} .
\end{gathered}
$$




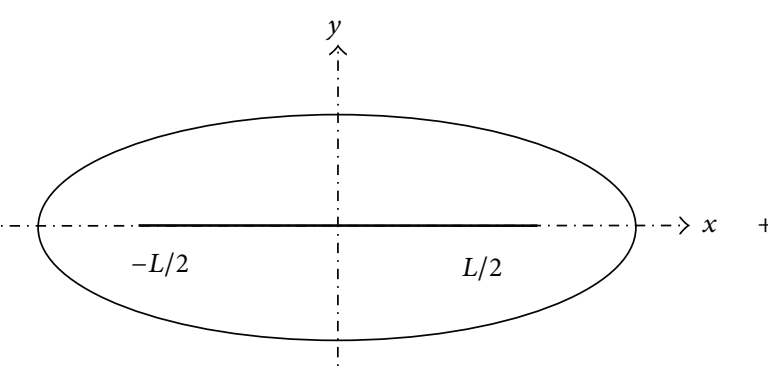

(a)

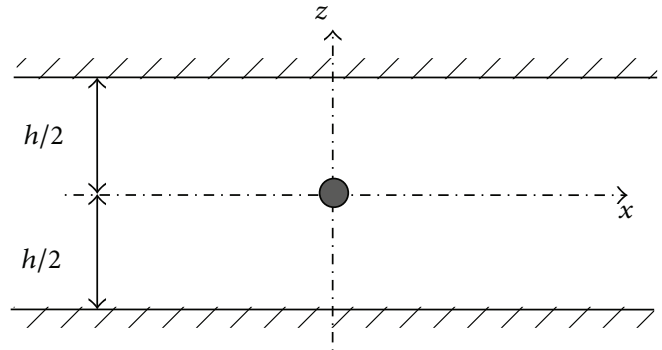

(b)

FIGURE 2: Schematic of the fluid flow to a horizontal well: (a) horizontal plane and (b) vertical plane.

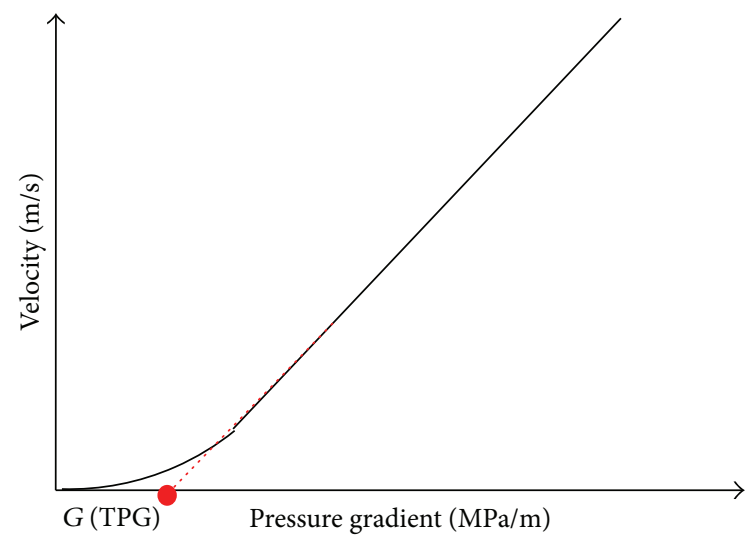

FIGURE 3: A schematic of core sample laboratory experiments in low-permeability reservoir.

So, as shown in Figure 4, the fluid flow in the $u$ - $v$ plane can be viewed as a unit radius vertical well produced at a circle drainage area with the radius of $(a+b) /(0.5 L)$. Combining the modified Darcy flow equation with the steady-state governing equation, the fluid flow in the horizontal plane can be described as

$$
\begin{gathered}
\frac{1}{r} \frac{\mathrm{d}}{\mathrm{d} r}\left[r e^{-\alpha_{k}\left(p_{i}-p\right)} \lambda_{t}\left(\frac{\mathrm{d} p}{\mathrm{~d} r}-G^{\prime}\right)\right]=0, \\
\left.p\right|_{r=1}=p_{c}, \\
\left.p\right|_{r=r_{e H}}=p_{i},
\end{gathered}
$$

where $\lambda_{t}$ is the total mobility of the oil/water phase, $\lambda_{t}=$ $k_{r o} / \mu_{o}+k_{r w} / \mu_{w}$, which is a function of the radius, and $G^{\prime}$ is the equivalent threshold pressure gradient in the horizontal plane, which is

$$
G^{\prime}=\frac{G\left(r_{e}-L / 2\right)}{((a+b) / 0.5 L)-1} .
$$

The solution of mathematical models of (11)-(13) is (the detailed derivations are showed in the Appendix)

$$
\begin{aligned}
& p(r)=p_{i} \\
& +\frac{1}{\alpha_{k}} \ln \left\{e ^ { \alpha _ { k } G ^ { \prime } r } \left[e^{-\alpha_{k}\left(G^{\prime}+p_{i}-p_{c}\right)}\right.\right. \\
& +\frac{e^{-\alpha_{k} G^{\prime} r_{e H}}-e^{-\alpha_{k}\left(G^{\prime}+p_{i}-p_{c}\right)}}{\int_{1}^{r_{e H}} e^{-\alpha_{k} G^{\prime} r} \cdot\left(1 / r \lambda_{t}(r)\right) \mathrm{d} r} \\
& \left.\left.\cdot \int_{1}^{r} e^{-\alpha_{k} G^{\prime} r} \frac{1}{r \lambda_{t}(r)} \mathrm{d} r\right]\right\} .
\end{aligned}
$$
by

The liquid flow rate in horizontal plane can be calculated

$$
q_{L H}=C h k \lambda_{t}(1) \cdot\left(r \frac{\mathrm{d} p}{\mathrm{~d} r}\right)_{r=1},
$$

where $C$ is the unit conversion factor, $C=542 ; q_{L H}$ is the liquid flow rate at reservoir condition, $\mathrm{m}^{3} / \mathrm{d}$.

Combining (15) with (16), the liquid flow rate in the horizontal plane is

$$
\begin{aligned}
q_{L H}= & C k_{i} e^{-\alpha_{k}\left(p_{i}-p_{c}\right)} h \\
& \cdot\left\{\lambda_{t}(1) \cdot G^{\prime}\right. \\
& \left.\quad+\frac{\left[e^{-\alpha_{k}\left[G^{\prime} r_{e H}-\left(p_{i}-p_{c}\right)\right]}-e^{-\alpha_{k} G^{\prime}}\right]}{\left(\alpha_{k} \int_{1}^{r_{e H}} e^{-\alpha_{k} G^{\prime} r} \cdot\left(1 / r \lambda_{t}(r)\right) \mathrm{d} r\right)}\right\} .
\end{aligned}
$$

The corresponding oil production rate in the horizontal plane is

$$
\begin{aligned}
q_{o H}= & C k_{i} e^{-\alpha_{k}\left(p_{i}-p_{c}\right)} h \lambda_{o}(1) \\
& \cdot\left[G^{\prime}+\frac{1}{\lambda_{t}(1)} \cdot \frac{e^{-\alpha_{k}\left[G^{\prime} r_{e H}-\left(p_{i}-p_{c}\right)\right]}-e^{-\alpha_{k} G^{\prime}}}{\alpha_{k} \int_{1}^{r_{e H}} e^{-\alpha_{k} G^{\prime} r} \cdot\left(1 / r \lambda_{t}(r)\right) \mathrm{d} r}\right],
\end{aligned}
$$




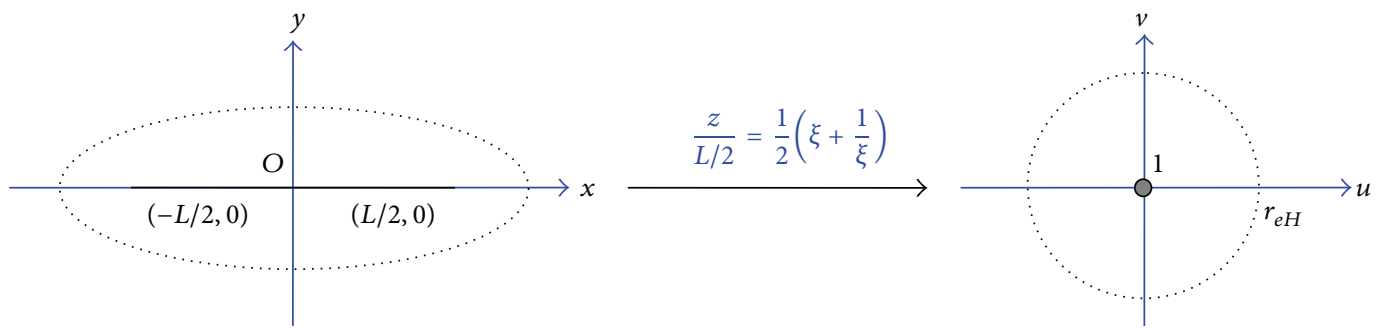

FIgURE 4: The schematic of fluid flow in horizontal plane after conformal transformation.

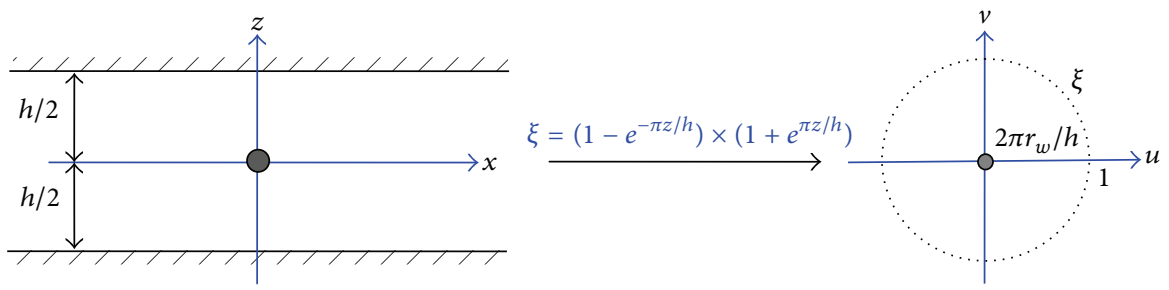

FIGURE 5: The schematic of fluid flow in vertical plane after conformal transformation.

where $q_{o H}$ is the oil flow rate at reservoir condition, $\mathrm{m}^{3} / \mathrm{d}$; $\lambda_{t}\left(r_{w}\right)$ is the total mobility of the oil/water phase in the well bottomhole, $\mathrm{D} / \mathrm{cp}$.

If we do not take into account the effects of permeability stress-sensitive and threshold pressure gradient on the productivity equation in horizontal plane $\left(\alpha_{k}=G=0\right)$ and assume only oil flow in the formation $\left(\lambda_{t}(r)=1 / \mu_{o}\right)$, then (17) becomes

$$
q_{\mathrm{SOH}}=\frac{0.542 \times 10^{-3} k_{i} h\left(p_{i}-p_{c}\right)}{B_{o} \mu_{o} \ln (2(a+b) / L)},
$$

where $q_{\mathrm{sOH}}$ is the oil flow rate at surface condition, $\mathrm{m}^{3} / \mathrm{d} ; B_{o}$ is the oil volume factor, $\mathrm{sm}^{3} / \mathrm{m}^{3}$.

Equation (19) is the same as the productivity equation in horizontal plane of (1) derived by Joshi [7].

2.5. Calculation of Flow in a Vertical Plane. The fluid flow in the vertical plane with top and bottom boundaries closed reservoir can be viewed as a vertical well with the radius of $\xi_{w}=2 \pi r_{w} / h$ produced in a unit circle area after the conformal transformation (as shown in Figure 5).

The mathematical models to describe the steady-state fluid flow of oil/water flow in the vertical plane are

$$
\begin{gathered}
\frac{1}{r} \frac{\mathrm{d}}{\mathrm{d} r}\left[r e^{-\alpha_{k}\left(p_{i}-p\right)} \lambda_{t}\left(\frac{\mathrm{d} p}{\mathrm{~d} r}-G^{\prime \prime}\right)\right]=0, \\
\left.p\right|_{r=\xi_{w}}=p_{w f} \\
\left.p\right|_{r=1}=p_{c}
\end{gathered}
$$

where $G^{\prime \prime}$ is the equivalent threshold pressure gradient in the vertical plane, which is

$$
G^{\prime \prime}=\frac{(h / 2)-r_{w}}{1-\left(2 \pi r_{w} / h\right)} G
$$

The solution of the pressure distribution along the radius can be solved with the same method showed in the Appendix. Then, the productivity equation in the vertical plane can be calculated by the following equation:

$$
q_{L V}=C L k \lambda_{t}\left(\xi_{w}\right) \cdot\left(r \frac{\mathrm{d} p}{\mathrm{~d} r}\right)_{r=\xi_{w}} .
$$

The liquid and oil productivity in the vertical plane are

$$
\begin{aligned}
& q_{L V}=C k_{i} e^{-\alpha_{k}\left(p_{c}-p_{w f}\right)} L \\
& \left\{\lambda_{t}\left(\xi_{w}\right) \cdot G^{\prime \prime} \cdot \xi_{w}\right. \\
& \left.+\frac{\left[e^{-\alpha_{k}\left[G^{\prime \prime}-\left(p_{c}-p_{w f}\right)\right]}-e^{-\alpha_{k} G^{\prime \prime} \xi_{w}}\right]}{\left(\alpha_{k} \int_{\xi_{w}}^{1} e^{-\alpha_{k} G^{\prime \prime} r} \cdot\left(1 / r \lambda_{t}(r)\right) \mathrm{d} r\right)}\right\}, \\
& q_{o V}=C k_{i} e^{-\alpha_{k}\left(p_{c}-p_{w f}\right)} L \lambda_{o}\left(\xi_{w}\right) \\
& \times\left\{G^{\prime \prime} \cdot \xi_{w}\right. \\
& \left.+\frac{\left[e^{-\alpha_{k}\left[G^{\prime \prime}-\left(p_{c}-p_{w f}\right)\right]}-e^{-\alpha_{k} G^{\prime \prime} \xi_{w}}\right]}{\left(\lambda_{t}\left(\xi_{w}\right) \alpha_{k} \int_{\xi_{w}}^{1} e^{-\alpha_{k} G^{\prime \prime} r} \cdot\left(1 / r \lambda_{t}(r)\right) \mathrm{d} r\right)}\right\} .
\end{aligned}
$$

Assuming the reservoir with single phase flow and neglecting the permeability stress-sensitive and threshold pressure gradient $\left(\alpha_{k}=G=0, \lambda_{t}(r)=1 / \mu_{o}\right)$ yield

$$
q_{o V}=\frac{C k_{i} L\left(p_{c}-p_{w f}\right)}{B_{o} \mu_{o} \ln \left(h / 2 r_{w}\right)} .
$$


Equation (23) is similar to the productivity equation in vertical plane of (D-3) derived by Joshi [7], which proves the correctness of the productivity equation in this paper.

2.6. Horizontal Well Eccentricity. Figure 5 and $(*)-(* *)$ are obtained under the assumption that the horizontal well is located at the center of the reservoir in the vertical plane. According to Muskat's [29] formulation for off-centered wells, the liquid production rate of a well placed at a distance $\delta$ from the mid-height of the reservoir in a vertical plane is

$$
\begin{aligned}
& q_{L V}=C k_{i} e^{-\alpha_{k}\left(p_{c}-p_{w f}\right)} h \\
& \left\{\lambda_{t}\left(\xi_{w}\right) \cdot G^{\prime} \cdot \xi_{w}\right. \\
& \left.+\frac{\left[e^{-\alpha_{k}\left[G^{\prime} \beta-\left(p_{c}-p_{w f}\right)\right]}-e^{-\alpha_{k} G^{\prime} \xi_{w}}\right]}{\left(\alpha_{k} \int_{\xi_{w}}^{\beta} e^{-\alpha_{k} G^{\prime} r} \cdot\left(1 / r \lambda_{t}(r)\right) \mathrm{d} r\right)}\right\} .
\end{aligned}
$$

The oil production rate is

$$
\begin{aligned}
q_{o V}= & C k_{i} e^{-\alpha_{k}\left(p_{c}-p_{w f}\right)} h \lambda_{o}\left(\xi_{w}\right) \\
& \times\left\{G^{\prime \prime} \cdot \xi_{w}\right. \\
& \left.+\frac{\left[e^{-\alpha_{k}\left[G^{\prime \prime} \beta-\left(p_{c}-p_{w f}\right)\right]}-e^{-\alpha_{k} G^{\prime \prime} \xi_{w}}\right]}{\left(\lambda_{t}\left(\xi_{w}\right) \alpha_{k} \int_{\xi_{w}}^{\beta} e^{-\alpha_{k} G^{\prime \prime} r} \cdot\left(1 / r \lambda_{t}(r)\right) \mathrm{d} r\right)}\right\},
\end{aligned}
$$

where $\delta$ is the vertical distance between the reservoir center and horizontal well location, $\mathrm{m} ; \beta=1-(2 \delta / h)^{2}$.

\section{The Solving Method of $\lambda_{t}(r)$}

In order to correctly calculate the productivity of horizontal well with oil/water phase flow, we must determinate the expression of total mobility, $\lambda_{t}(r)$, along the radius $r$. The following steps are the procedure to calculate it.

Step 1. According to the relative permeability curves and the viscosity of oil and water, the relationship between $\lambda_{t}(r)$ and $S_{w}$ can be obtained.

Step 2. When the water displacement front breaks through the oil well, the distribution of water saturation along the well radius satisfies the following Buckley-Leverett equation:

$$
\pi h \phi\left(r_{e}^{2}-r^{2}\right)=\frac{\mathrm{d} f_{w}}{\mathrm{~d} s_{w}} \cdot \sum Q_{l},
$$

where $h$ is the formation thickness, $\mathrm{m} ; \phi$ is the porosity, fraction; $\sum Q_{l}$ is the cumulative fluid production, $\mathrm{m}^{3} / \mathrm{d} ; f_{w}$ is the water ratio, fraction, $f_{w}=\left(k_{r w} / \mu_{w}\right) /\left(k_{r o} / \mu_{o}\right)+\left(k_{r w} / \mu_{w}\right)$.

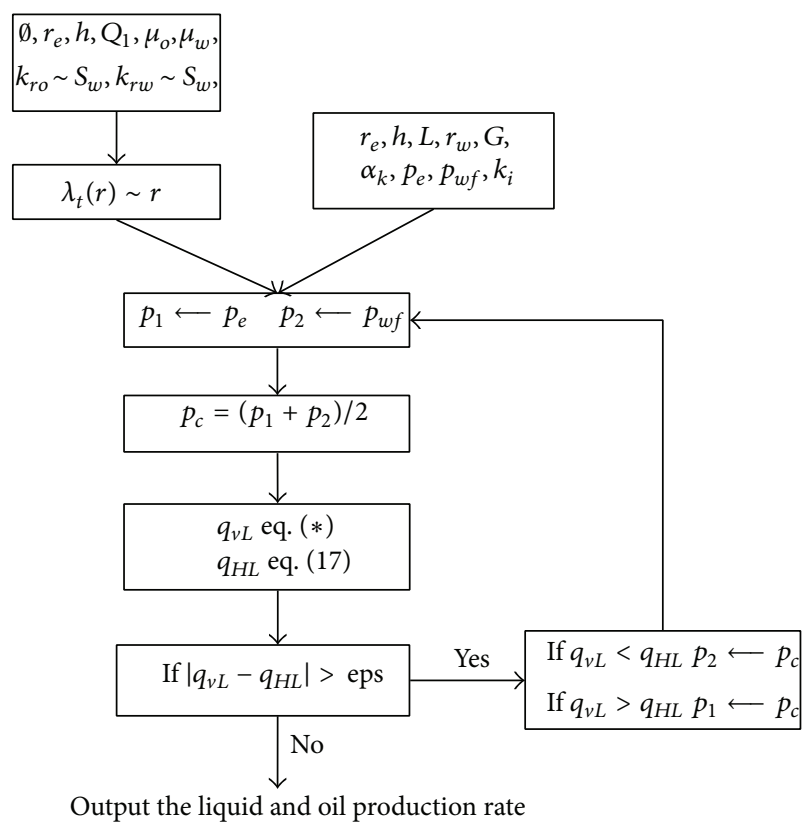

FIgURE 6: The productivity calculation diagram.

In (24), the expressions of the $\mathrm{d} f_{w} / \mathrm{d} S_{w}$ versus $s_{w}$ can be calculated by the relative permeability curves.

Step 3. Combining the relationship of $\lambda_{t}(r)$ versus $S_{w}$ and $S_{w}$ versus $r$ derived in Steps 1 and 2, the relationship of $\lambda_{t}(r)$ with $r$ can be obtained.

Statistical results show that the relationships of $S_{w}$ versus $r, \lambda_{t}(r)$ versus $S_{w}$, and $\lambda_{t}(r)$ versus $r$ can be approximated by the following analytical functions:

$$
\begin{gathered}
S_{w}(r)=a_{1}+b_{1} r^{2}, \\
\lambda_{t}\left(S_{w}\right)=a_{2}+b_{2} S_{w}+c_{2} S_{w}^{2}, \\
\lambda_{t}(r)=a_{3}+b_{3} r^{2}+c_{3} r^{4} .
\end{gathered}
$$

\section{The Productivity Calculation Process}

Using the electrical analog concept, the well production rate in the horizontal plane must equal the production rate in the vertical plane. Because of the nonlinearity of (17)-(18) and $(*)-(* *)$, we cannot obtain productivity expressions similar to Joshi [7]. With the aid of computer programs, the results can be obtained and the calculation diagram is showed in Figure 6.

\section{Results and Their Sensitive Analysis}

In this section, the liquid and oil production rate are calculated, and the essential parameters of well, reservoir, and fluid properties are listed in Table 1, and the relative permeability curves are showed in Figure 7.

According to the relative permeability curves and the parameters in Table 1, the relationship of $\lambda_{t}\left(S_{w}\right)$ versus $S_{w}$ 


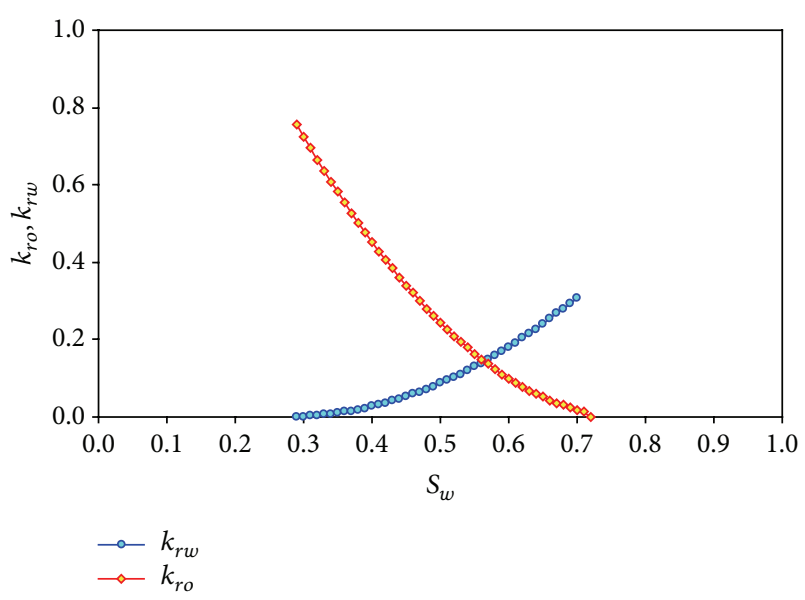

FIGURE 7: The relative permeability curves.

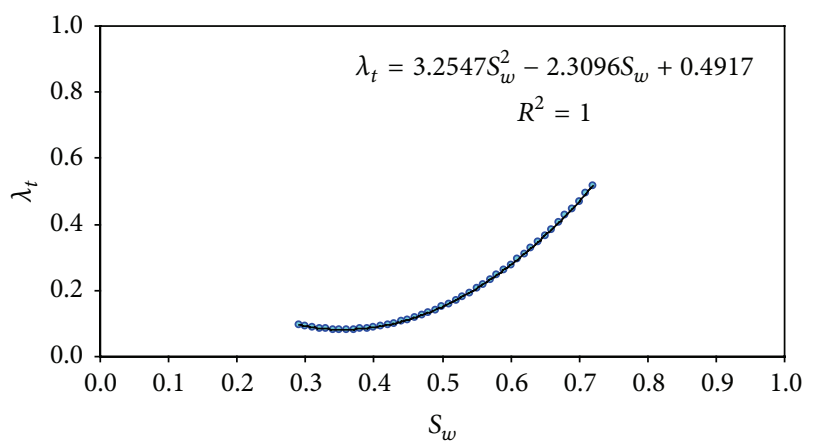

FIGURE 8: The relationship between $\lambda_{t}\left(S_{w}\right)$ and $S_{w}$.

TABLE 1: The parameters of reservoir and fluid properties.

\begin{tabular}{lc}
\hline Variables & value \\
\hline Porosity, $\emptyset$ (fraction) & 0.05 \\
Drainage radius, $r_{e}(\mathrm{~m})$ & 600 \\
Horizontal well length, $L(\mathrm{~m})$ & 300 \\
Initial permeability of the reservoir, $k_{i}(\mathrm{D})$ & $2 \times 10^{-3}$ \\
Cumulative fluid production, $\sum Q_{l}\left(\mathrm{~m}^{3}\right)$ & $1.14 \times 10^{6}$ \\
Oil viscosity in the reservoir, $\mu_{o}(\mathrm{mPa} \cdot \mathrm{s})$ & 3 \\
Formation thickness, $h(\mathrm{~m})$ & 20 \\
Initial reservoir pressure, $p_{e}(\mathrm{MPa})$ & 30 \\
Permeability modulus, $\alpha_{k}\left(\mathrm{MPa}{ }^{-1}\right)$ & 0.1 \\
Water saturation in the bottomhole, $S_{w B}($ fraction$)$ & 0.6 \\
Threshold pressure gradient, $G(\mathrm{MPa} / \mathrm{m})$ & 0.001 \\
Water viscosity in the reservoir, $\mu_{w}(\mathrm{mPa} \cdot \mathrm{s})$ & 1 \\
\hline
\end{tabular}

and $\mathrm{d} f_{w} / \mathrm{d} S_{w}$ versus $S_{w}$ can be plotted when water cut ratio reaches 0.6 (as shown in Figures 8 and 9). The corresponding regression curve equations can be obtained as follows:

$$
\begin{aligned}
\lambda_{t} & =0.4917-2.3096 S_{w}+3.2547 S_{w}^{2}, \\
\frac{\mathrm{d} f_{w}}{\mathrm{~d} S_{w}} & =-6.0226 S_{w}+4.3193, \quad S_{w}>0.6
\end{aligned}
$$

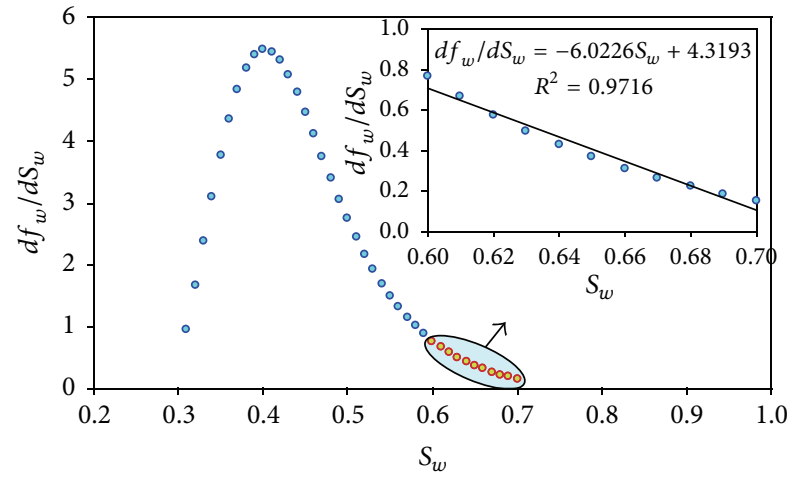

FIgURE 9: The relationship between $\mathrm{d} f_{w} / \mathrm{d} S_{w}$ and $S_{w}$.

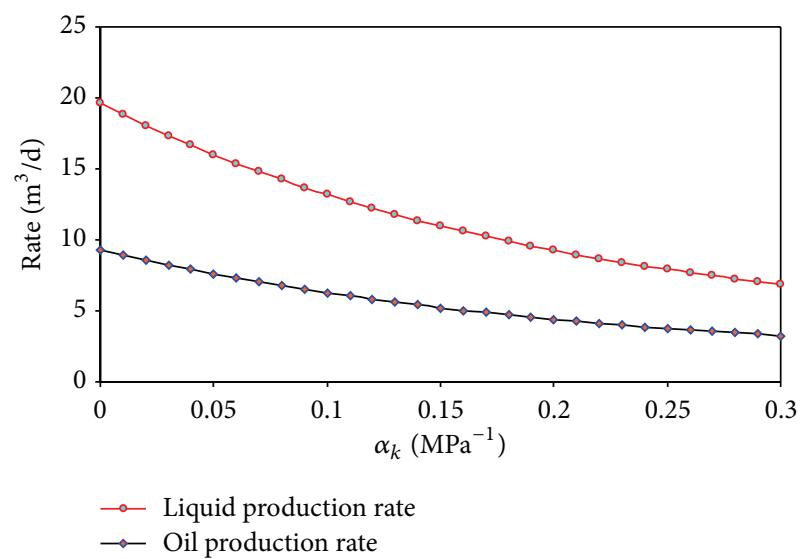

FIGURE 10: The effect of permeability modulus $\left(\alpha_{k}\right)$ on liquid production rate.

Taking (26) as well as the cumulative fluid production into (24), the expressions between the $\lambda_{t}(r)$ and $r$ can be obtained, which is

$$
\lambda_{t}=0.2+1.53 \times 10^{-6} r^{2}+6.8 \times 10^{-13} r^{4} .
$$

Combining (27) and other parameters in Table 1 with (17)-(18) and $(*)-(* *)$, the steady-state fluid productivity can be calculated.

Figure 10 shows the effect of permeability modulus $\alpha_{k}$ on liquid and oil productivity of horizontal well in low permeability reservoir. It can be seen from the figure that the permeability stress-sensitive has a significant effect on the productivity; the bigger the $\alpha_{k}$ is, the smaller the liquid and oil productivity are, which is mainly because, with the same pressure drop of the reservoir, big $\alpha_{k}$ will lead to a serious permeability decreasing. When we do not take into account the permeability stress sensitive $\left(\alpha_{k}=0\right)$, the liquid and oil productivity can be calculated with the limit of $\alpha_{k}$ tending to zero for (17)-(18) and $(*)-(* *)$.

Figures 11 and 12 show the effect of threshold pressure gradient $(G)$ and well length $(L)$ on liquid and oil productivity. It can be seen from the chart that the threshold pressure gradient has small effect on the productivity of horizontal well for big drainage volume. In general, the bigger 
TABLE 2: The productivity of liquid and oil in different bottomhole pressure.

\begin{tabular}{lcccc}
\hline $\begin{array}{l}p_{w f} \\
(\mathrm{MPa})\end{array}$ & $\begin{array}{c}\alpha_{k}=0.1, G=0.001 \\
\text { Liquid production rate } \\
\left(\mathrm{m}^{3} / \mathrm{d}\right)\end{array}$ & $\begin{array}{c}\text { Oil production rate } \\
\left(\mathrm{m}^{3} / \mathrm{d}\right)\end{array}$ & $\begin{array}{c}\alpha_{k}=0, G=0 \\
\text { Liquid production rate } \\
\left(\mathrm{m}^{3} / \mathrm{d}\right)\end{array}$ & $\begin{array}{c}\text { Oil production rate } \\
\left(\mathrm{m}^{3} / \mathrm{d}\right)\end{array}$ \\
\hline 30.00 & 0.00 & 0.00 & 0.00 & 0.00 \\
29.80 & 0.00 & 0.00 & 0.39 & 0.19 \\
29.60 & 0.00 & 0.00 & 0.79 & 0.37 \\
29.50 & 0.33 & 0.16 & 0.98 & 0.47 \\
27.00 & 4.58 & 2.18 & 5.89 & 2.80 \\
24.00 & 8.61 & 4.09 & 11.77 & 5.60 \\
21.00 & 11.71 & 5.56 & 17.66 & 8.40 \\
18 & 14.07 & 6.69 & 23.5 & 11.19 \\
15 & 15.85 & 7.54 & 29.44 & 13.99 \\
2 & 17.20 & 8.18 & 35.32 & 16.79 \\
\hline
\end{tabular}

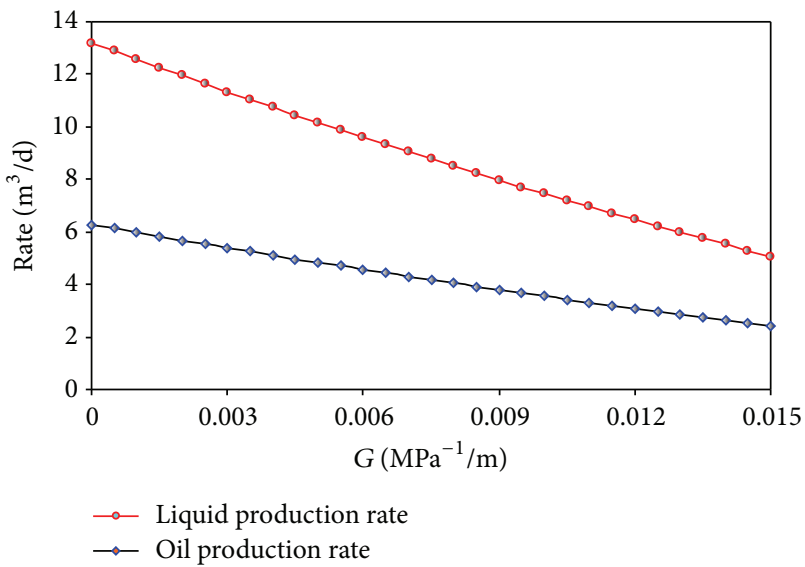

Figure 11: The effect of threshold pressure gradient $(G)$ on liquid production rate.

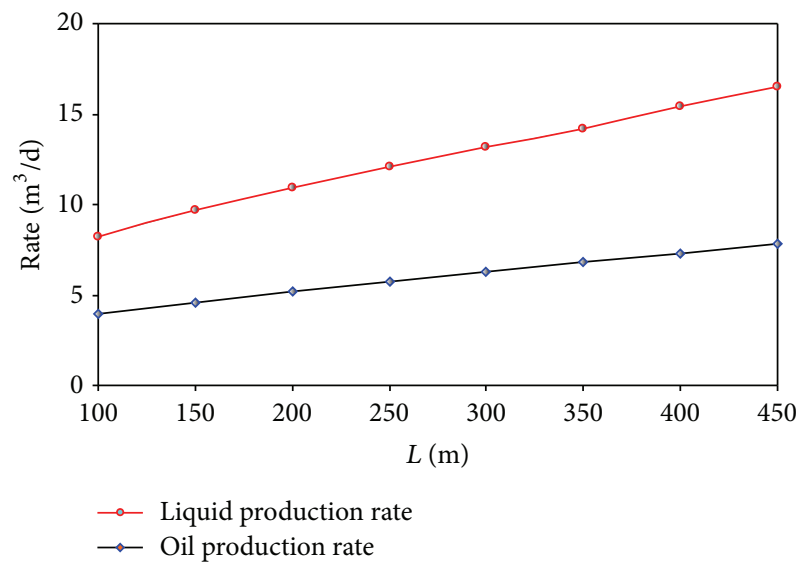

FIGURE 12: The effect of well length $(L)$ on liquid production rate.

the $G$ is, the smaller the liquid and oil productivity are. When the reservoir has both threshold pressure gradient and permeability stress sensitive, the longer the well length is, the bigger the productivity is.

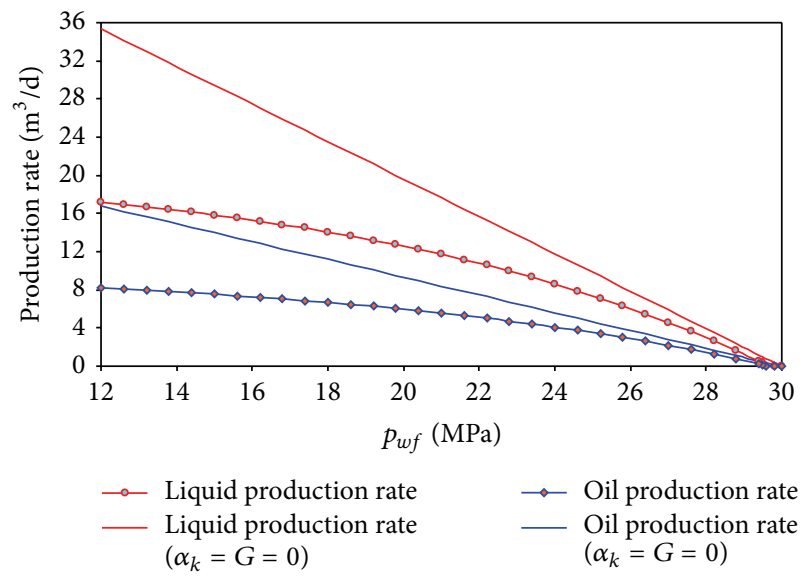

FIGURE 13: The productivity of horizontal well in different bottomhole pressure.

Figure 13 shows the liquid productivity with different bottomhole pressure when $\alpha_{k}=0.1, G=0.001$ and $\alpha_{k}=$ $0, G=0$, the corresponding values are listed in Table 2 . It can be clearly seen that the permeability stress-sensitive and threshold pressure gradient have significant effects on the well productivity, and the bigger $\alpha_{k}$ and $G$ are, the more obvious the effect is. And when the pressure drop is small, the fluid cannot flow for the existing of threshold pressure gradient, which is mainly because only the fluid can flow when the pressure drop overcomes the threshold pressure for multiphase flow.

\section{Conclusions}

In this paper, a semianalytical productivity equation of horizontal well in low-permeability oil reservoir with oil/water two-phase flow is established with the consideration of permeability stress-sensitive and threshold pressure gradient. Based on the above study, the following conclusions can be summarized. 
(1) The steady-state percolation mathematical models of horizontal well with oil/water two-phase flow are established and the corresponding solutions are solved by the method of separation of variables.

(2) For low-permeability reservoir, there always exists the phenomenon of permeability stress-sensitive $\left(\alpha_{k}\right)$, which has a significant influence on the well productivity; the bigger the $\alpha_{k}$ is, the smaller the productivity is.

(3) Due to the existence of capillary pressure of twophase flow, there always is threshold pressure gradient $(G)$ in the fluid seepage process. Although the $G$ has a smaller effect on the productivity of the horizontal well for a big drainage volume, we cannot neglect its effect on the productivity.

\section{Appendix}

From the expressions of (11), we have

$$
r \lambda_{t} e^{-\alpha_{k}\left(p_{i}-p\right)}\left(\frac{\mathrm{d} p}{\mathrm{~d} r}-G^{\prime}\right)=c,
$$

where $c$ is a constant.

We define the following expression:

$$
y=e^{-\alpha_{k}\left(p_{i}-p\right)} \text {. }
$$

Substituting (A.2) into (A.1) and (12)-(13) yields

$$
\begin{gathered}
\frac{\mathrm{d} y}{\mathrm{~d} r}=\alpha_{k} G^{\prime} y+\frac{c \alpha_{k}}{r \lambda_{t}}, \\
\left.y\right|_{r=1}=e^{-\alpha_{k}\left(p_{i}-p_{c}\right)}, \\
\left.y\right|_{r=r_{e H}}=1 .
\end{gathered}
$$

According to the general solution of the Bernoulli differential equation [30], the solution of (A.3) can be obtained as

$$
\begin{aligned}
y(r)= & e^{\alpha_{k} G^{\prime} r} \\
& \cdot\left[e^{-\alpha_{k} G^{\prime}} e^{-\alpha_{k}\left(p_{i}-p_{c}\right)}+\int_{r_{w}}^{r} e^{-\alpha_{k} G^{\prime} r} \frac{c \alpha_{k}}{r \lambda_{t}(r)} \mathrm{d} r\right] .
\end{aligned}
$$

Substituting (A.6) into (A.5), the value of constant $c$ can be solved, and then combining it with (A.6), we have

$$
\begin{aligned}
& p(r) p_{i}+\frac{1}{\alpha_{k}} \ln \left\{e^{\alpha_{k} G^{\prime} r}\right. \\
& \cdot {\left[e^{-\alpha_{k}\left(G^{\prime}+p_{i}-p_{c}\right)}+\frac{e^{-\alpha_{k} G^{\prime} r_{e H}}-e^{-\alpha_{k}\left(G^{\prime}+p_{i}-p_{c}\right)}}{\int_{r_{w}}^{r_{e} H} e^{-\alpha_{k} G^{\prime} r} \cdot\left(1 / r \lambda_{t}(r)\right) \mathrm{d} r}\right.} \\
&\left.\left.\cdot \int_{r_{w}}^{r} e^{-\alpha_{k} G^{\prime} r} \frac{1}{r \lambda_{t}(r)} \mathrm{d} r\right]\right\} .
\end{aligned}
$$

Equation (A.7) is the pressure distribution relation along the radius $r$ with the oil/water two-phase flows in the horizontal plane of the horizontal well.

\section{Conflict of Interests}

The authors declare that there is no conflict of interests regarding the publication of this paper.

\section{Acknowledgments}

This work was supported by the Natural Science Foundation of China (Grant no. 51374181) and the project of National Science Fund for Distinguished Young Scholars of China (Grant no. 51125019). The authors would also like to thank the reviewers and editors for their patience to read this paper and valuable comments.

\section{References}

[1] V. P. Merkulov, "Le debit des puits devies et horizontaux," Neft. Khoz, vol. 6, no. 1, pp. 51-56, 1958.

[2] J. P. Borisov, Oil Production Using Horizontal and Multiple Deviation Wells, The R\&D Translation Company, Bartlesville, Okla, USA, 1984.

[3] F. M. Giger, L. H. Reiss, and A. P. Jourdan, "The reservoir engineering aspects of horizontal drilling," in Proceedings of the 59th Annual Technical Conference and Exhibition, Houston, Tex, USA, 1984.

[4] F. M. Giger, "Horizontal wells production techniques in heterogeneous reservoirs," in Proceedings of the Middle East Oil Technical Conference and Exhibition, Bahrain, 1985.

[5] B. J. Karcher and F. M. Giger, "Some practical formulas to predict horizontal well behavior," in Proceedings of the SPE Annual Technical Conference and Exhibition, New Orleans, La, USA, 1986.

[6] L. H. Reiss, "Production from horizontal wells after five years," Journal of Petroleum Technology, vol. 39, no. 11, pp. 1411-1416, 1987.

[7] S. D. Joshi, "Augmentation of well productivity using slant and horizontal wells," Journal of Petroleum Technology, vol. 40, no. 6, pp. 729-739, 1988.

[8] D. K. Babu and A. S. Odeh, "Productivity of a horizontal well," SPE Reservoir Engineering, vol. 4, no. 4, pp. 417-421, 1989.

[9] G. Renard and J. M. Dupuy, "Formation damage effects on horizontal-well flow efficiency," Journal of Petroleum Technology, vol. 43, no. 7, pp. 786-789, 1991.

[10] M. W. Helmy and R. A. Wattenbarger, "Simplified productivity equations for horizontal wells producing at constant rate and constant pressure," in Proceedings of the SPE Technical Conference and Exhibition, pp. 379-388, New Orleans, La, USA, September 1998.

[11] T. Billiter, J. Lee, and R. Chase, "Dimensionless inflow-performance-relationship curve for unfractured horizontal gas wells," in Proceedings of the SPE Eastern Regional Meeting, Canton, Ohio, USA, 2001

[12] E. G. Anklam and M. L. Wiggins, "Horizontal well productivity and wellbore pressure behavior incorporating wellbore hydraulics," in Proceedings of the SPE Production and Operations 
Symposium, pp. 565-584, Oklahoma City, Okla, USA, April 2005.

[13] J. Lu, "New productivity formulae of horizontal wells," Journal of Canadian Petroleum Technology, vol. 40, no. 10, pp. 55-67, 2001.

[14] F. Samaniego, W. E. Brigham, and F. G. Miller, "Performanceprediction procedure for transient flow of fluids through pressure-sensitive formations," Journal of Petroleum Technology, vol. 31, no. 6, pp. 779-786, 1979.

[15] G. K. Falade, "Transient flow of fluids in reservoirs with stress sensitive rock and fluid properties," International Journal of Non-Linear Mechanics, vol. 17, no. 4, pp. 277-283, 1982.

[16] R. W. Ostensen, "Microcrack Permeability in tight gas sandstone," Society of Petroleum Engineers Journal, vol. 23, no. 6, pp. 919-927, 1983.

[17] J. Pedrosa and O. A. Petrobras, "Pressure transient response in stress-sensitive formations," in Proceedings of the SPE California Regional Meeting, Oakland, Calif, USA, 1986.

[18] D. A. Barry, D. A. Lockington, D.-S. Jeng, J.-Y. Parlange, L. Li, and F. Stagnitti, "Analytical approximations for flow in compressible, saturated, one-dimensional porous media," Advances in Water Resources, vol. 30, no. 4, pp. 927-936, 2007.

[19] T. Friedel and H. D. Voigt, "Analytical solutions for the radial flow equation with constant-rate and constant-pressure boundary conditions in reservoirs with pressure-sensitive permeability," in Proceedings of the SPE Rocky Mountain Petroleum Technology Conference, Denver, Colo, USA, 2009.

[20] B. Ju, Y. Wu, and T. Fan, "Study on fluid flow in nonlinear elastic porous media: experimental and modeling approaches," Journal of Petroleum Science and Engineering, vol. 76, no. 3-4, pp. 205211, 2011.

[21] D. Swartzendruber, "Non-Darcy flow behavior in liquid saturated porous media," Journal of Geophysical Research, vol. 67, no. 13, pp. 5205-5213, 1962.

[22] R. J. Miller and F. L. Philip, "Threshold Gradient for water flow in clay system," Soil Science Society of America Journal, vol. 27, no. 6, pp. 605-609, 1963.

[23] H. W. Olsen, "Deviations from Darcy's law in saturated clays," Soil Science Society of America Journal, vol. 29, no. 2, pp. 135-140, 1965.

[24] H. Pascal, "Nonsteady flow through porous media in the presence of a threshold gradient," Acta Mechanica, vol. 39, no. 3-4, pp. 207-224, 1981.

[25] A. Prada and F. Civan, "Modification of Darcy's law for the threshold pressure gradient," Journal of Petroleum Science and Engineering, vol. 22, no. 4, pp. 237-240, 1999.

[26] J. Lu and S. Ghedan, "Pressure behavior of vertical wells in low-permeability reservoirs with threshold pressure gradient," Special Topics and Reviews in Porous Media, vol. 2, no. 3, pp. 157-169, 2011.

[27] Y. L. Zhao, L. H. Zhang, F. Wu, B. N. Zhang, and Q. G. Liu, "Analysis of horizontal well pressure behaviour in fractured low permeability reservoirs with consideration of the threshold pressure gradient," Journal of Geophysics and Engineering, vol. 10, no. 3, pp. 1-10, 2013.

[28] Y. L. Zhao, L. H. Zhang, J. Z. Zhao, S. Y. Hu, and B. N. Zhang, "Transient pressure analysis of horizontal well in low permeability oil reservoir," International Journal of Oil, Gas and Coal Technology, 2014.

[29] M. Muskat, The Flow of Homogeneous Fluids through a Porous Media, Intl., Human Resources Development Corp, Boston, Mass, USA, 1937.
[30] I. S. Gradshteyn and I. M. Ryzhik, Table of Integrals, Series and Products, Academic Press, San Diego, Calif, USA, Seventh edition, 2007. 


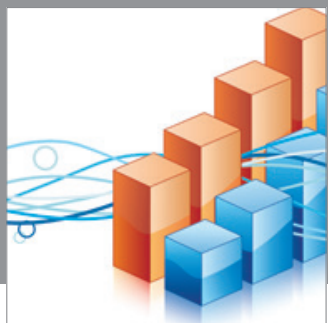

Advances in

Operations Research

mansans

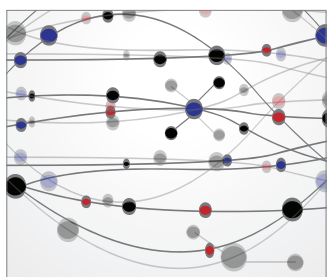

The Scientific World Journal
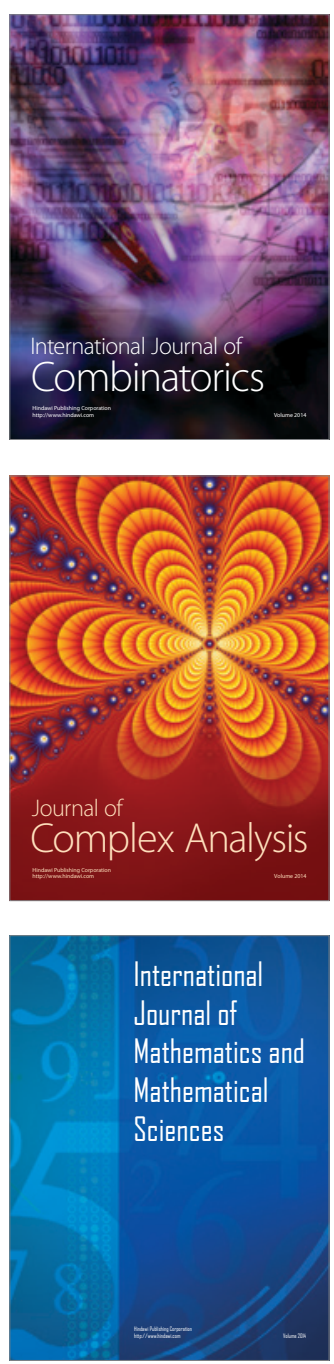
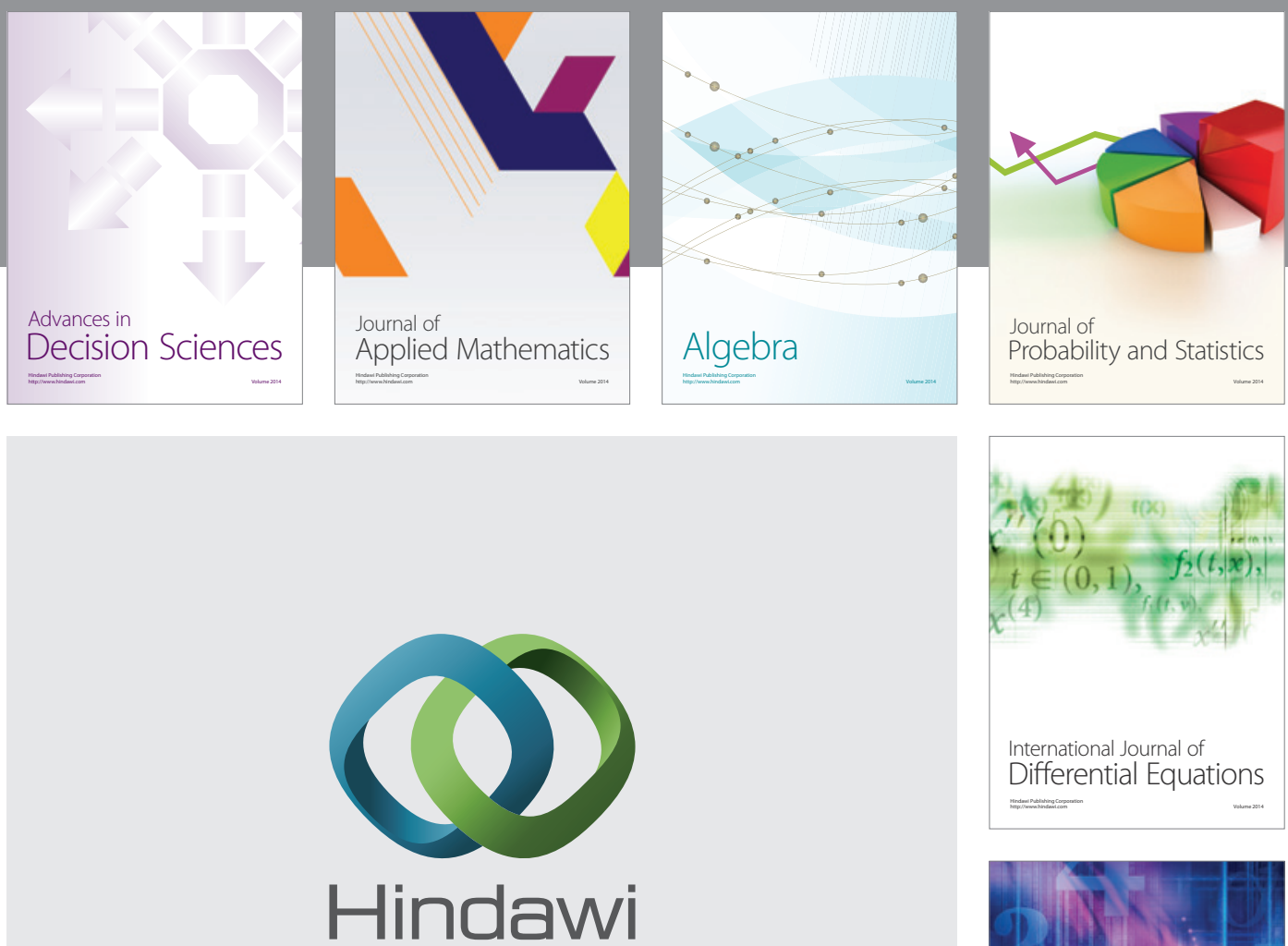

Submit your manuscripts at http://www.hindawi.com
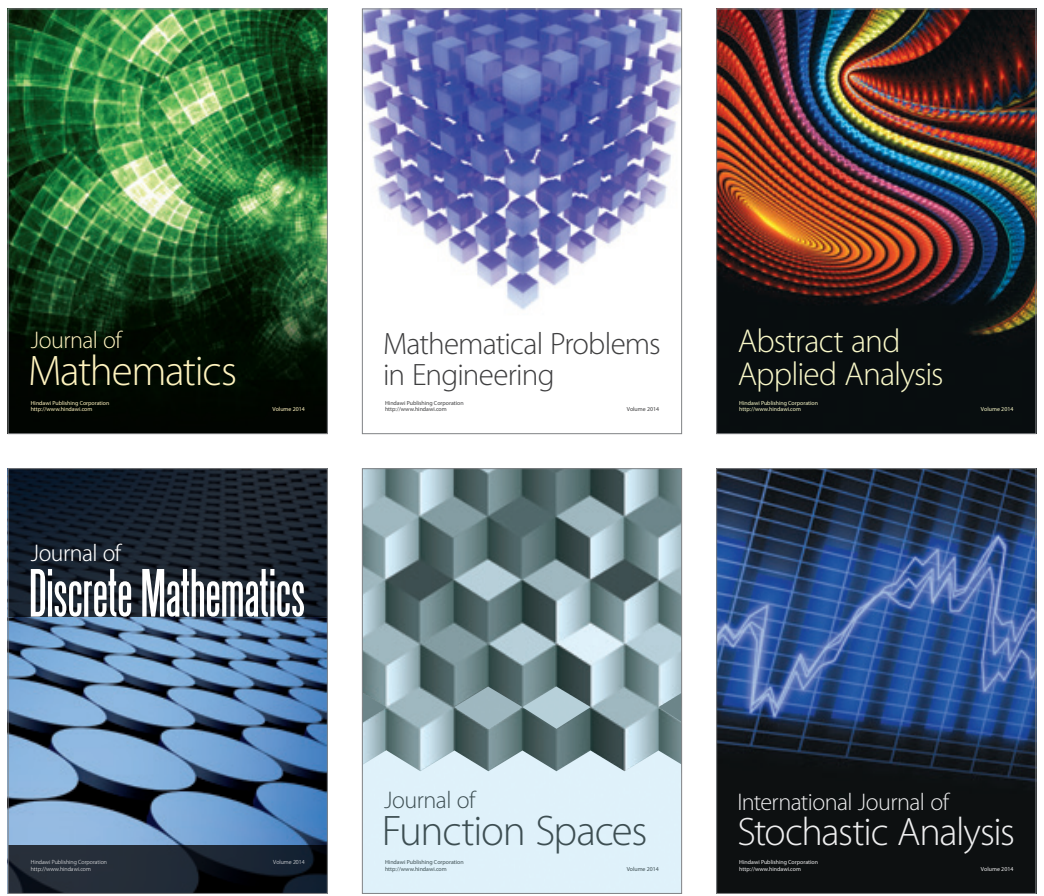

Journal of

Function Spaces

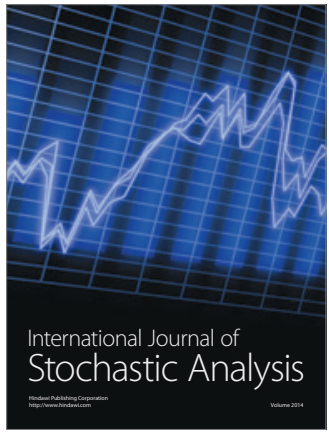

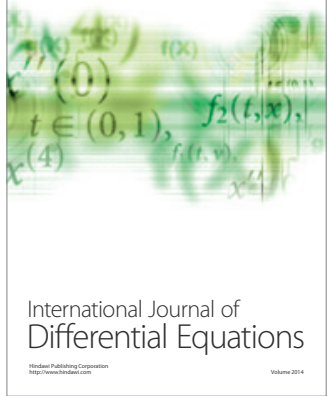
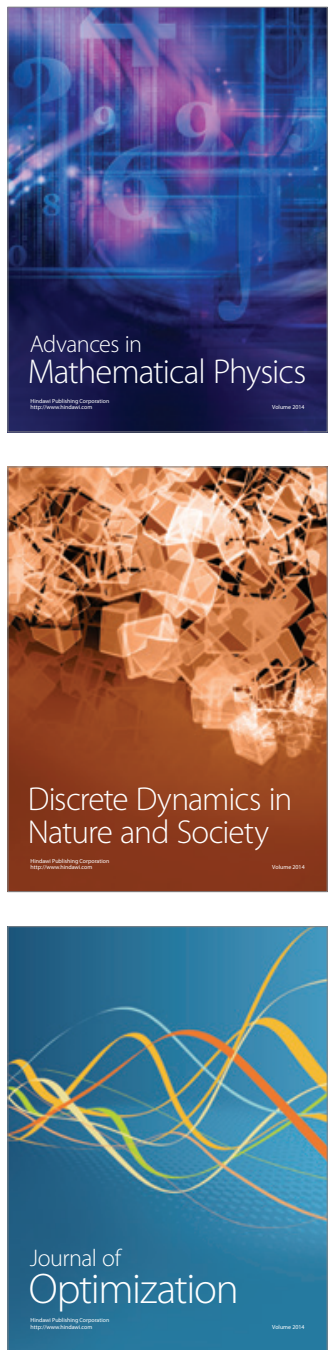